\title{
Safety perception of stairs with integrated lighting
}

Laurens Van de Perre ${ }^{\mathrm{a}, *}$, Stefan Danschutter ${ }^{\mathrm{b}}$, Kim Janssens ${ }^{\mathrm{c}}$, Peter Hanselaer ${ }^{\mathrm{a}}$, Marc Dujardin ${ }^{\mathrm{d}}$, Kevin A.G. Smet ${ }^{a}$, Wouter R. Ryckaert ${ }^{a}$

${ }^{a}$ KU Leuven, ESAT/Light\&Lighting Laboratory, Gebroeders De Smetstraat 1, 9000, Ghent, Belgium

${ }^{\mathrm{b}}$ Belgian Building Research Institute, Division 'Intelligent Installations \& Sustainable Solutions', Lozenberg 7, 1932, Sint-Stevens-Woluwe, Belgium

${ }^{\mathrm{c}}$ Hasselt University, Faculty of Architecture and Arts, Agoralaan Building E, 3590, Diepenbeek, Belgium

${ }^{\mathrm{d}} \mathrm{KU}$ Leuven, Faculty of Architecture, Hoogstraat 51, 9000, Ghent, Belgium

(C) 2019. This (accepted) manuscript version is made available under the CC-BY-NC-ND 4.0 license http://creativecommons.org/licenses/by-nc-nd/4.0/

DOI: https://doi.org/10.1016/i.buildenv.2019.106389

\begin{abstract}
Fall accidents on stairs occur regularly and can cause serious injuries. The risk of accidents increases with age. Many contributing factors are related to stair accidents such as personal and environmental factors. The presented research focuses on the influence of several lighting conditions on the perceived safety of a staircase in a dark environment. A mock-up staircase was built and the lighting consisted of a LED strip in the handrail illuminating the staircase and two LED strips in each stair nose mounted upwards and downwards. In total, 30 elderly observers evaluated the staircase on how safe they perceived the lighting scenes in order to descend the stairs. Results show an increased perceived safety when using the LED strip in either the handrail or the stair nose illuminating downwards. An increased intensity of the LED strip illuminating upwards resulted in a substantial decrease of the perceived safety. A model that accurately predicts the perceived safety is proposed. Input parameters of the model are the measured luminance values of the staircase. The model could also be used to design a staircase with an appropriate luminance distribution.
\end{abstract}

Keywords: Safety perception of stairs; Night-time situation; Elderly; Luminous model; Integrated lighting staircase design;

\section{INTRODUCTION}

Staircase accidents happen frequently and many of which result in serious injuries and sometimes death. In the United States 2285 deaths due to falls on and from stairs and steps were registered in 2014 , which represents approximately $7 \%$ of all fall related deaths [1]. Starting from about the age of 65 , falls become the leading cause of death, based on the percentage of unintentional deaths in the United States from 2014 [1]. According to [2], between $24 \%$ and $40 \%$ of the people over 65 years old and living at home fall, on average, once a year. This number increases for people with a higher risk profile, for example, up to $72 \%$ for persons with dementia. Using stairs is a very demanding and complicated task, especially when people age and some of their abilities deteriorate (e.g. astigmatism, stamina, reduced balance control) [3].

Fall incidents on stairs are mostly influenced by personal factors. Human behaviour, like using smartphones or carrying heavy items on stairs, but also human abilities, like visual performance or balance control, can increase the risk of falling. Environmental factors also contribute to stair accidents. Stair design characteristics have an impact on the prevalence of incidents and improving 
stair design can reduce fall accidents [4]. There are several requirements and standards for stair geometry [5], such as specifying the rise (vertical distance between two consecutive steps), going (horizontal distance between two consecutive nosings) and the pitch (angle between a step and nosing).

The Flemish Government investigated the quality of housing in 2013 [6], including a technical screening of about 5000 houses, representative for the Flemish housing stock. Stair safety was one of the most frequent occurring flaws: about $13 \%$ of the houses has one or more stairs with flaws, such as bad or missing handrails, stair too steep (e.g. $45^{\circ}$ ) or damaged stair surface [7]. The study contains no information about stair lighting. Some other studies investigating falls in homes of elderly people identified inadequate lighting to be one of the main factors contributing to a fall incident [8-10].

Prior to the current study, three exploratory studies were carried out which provided new insights on supportive lighting on staircases $[11,12]$. More particularly, these studies explored how sense of safety on staircases can be improved taking into account illuminance levels, lighting contrasts, pleasantness of different supportive lighting on staircases and preferable colour of steps. In order to gather a wide range of views and thoughts, participants of varying ages and occupations (such as students, designers and retirees) took part in these exploratory studies.

Based on the insights and results of these three exploratory studies, choices were made for the current study regarding (combinations of) luminaire groups on the staircase and step cover colour. A brainstorm session with the elderly participants revealed that safety on stairs is mostly compromised when descending the stairs, especially during night-time. Literature shows that more serious injuries are sustained when individuals fall while descending the stairs [13]. Therefore, in the current study a top-to-bottom view of the stairs in a dark environment was selected. Results also revealed that sufficient contrast between the steps of the stairs is important to achieve good stair safety perception.

It is clear that staircase lighting is important because it is directly linked to the visibility of the staircase. There are several specifications for staircase lighting such as the required average illuminance $\left(\bar{E}_{m}\right)$, uniformity $\left(U_{0}\right)$, limitation of glare, colour rendering $\left(C I E R_{a}\right)$ and contrast. A number of standards and guidance documents are available, such as the European standard EN 12464-1 [14], a practical and technical guide to home lighting [15], the ANSI/IES RP-28-16 [16], the CIBSE lighting guide 09 [17] and an inclusive design guidance [18]. An overview is shown in Table 1. 


\begin{tabular}{|c|c|c|c|c|c|}
\hline & EN 12464-1 & $\begin{array}{c}\text { Practical and } \\
\text { technical guide to } \\
\text { home lighting }\end{array}$ & $\begin{array}{c}\text { ANSI/IES RP- } \\
28-07\end{array}$ & $\begin{array}{l}\text { CIBSE lighting guide 09: } \\
\text { lighting for communal } \\
\text { residential buildings }\end{array}$ & $\begin{array}{l}\text { Inclusive design } \\
\text { guidance }\end{array}$ \\
\hline $\begin{array}{l}\text { Illuminance } \\
\left(\bar{E}_{m}\right)\end{array}$ & $100 \mathrm{~lx}$ & $75-150 \mathrm{~lx}$ & $100 \mathrm{~lx}$ & $\begin{array}{c}100 \mathrm{Ix} \text {, illuminate the } \\
\text { treads and keep the risers } \\
\text { in shadow }\end{array}$ & - \\
\hline $\begin{array}{l}\text { Uniformity } \\
\left(U_{0}\right)\end{array}$ & 0.40 & - & $\begin{array}{l}\text { Evenly light the } \\
\text { treads and } \\
\text { landing }\end{array}$ & & $\begin{array}{l}\text { All landings and } \\
\text { changes in level } \\
\text { should be well and } \\
\text { evenly illuminated }\end{array}$ \\
\hline Glare & $U G R_{L} \leq 25$ & Avoid downlights & $\begin{array}{l}\text { Excluding } \\
\text { luminaires with } \\
\text { strong surface } \\
\text { brightness in } \\
\text { the viewing } \\
\text { field }\end{array}$ & $\begin{array}{l}\text { Light fittings with } \\
\text { luminance no greater than } \\
300 \mathrm{~cd} / \mathrm{m}^{2}\end{array}$ & $\begin{array}{lr}\text { Avoid directional } \\
\text { spotlights; avoid glare }\end{array}$ \\
\hline $\begin{array}{l}\text { Colour } \\
\text { rendering } \\
\left(C I E R_{a}\right)\end{array}$ & 40 & - & - & & $\begin{array}{l}\text { Important for people } \\
\text { with visual } \\
\text { impairment }\end{array}$ \\
\hline $\begin{array}{l}\text { Specific } \\
\text { requirements }\end{array}$ & $\begin{array}{l}\text { Enhanced } \\
\text { contrasts on } \\
\text { the steps }\end{array}$ & - & $\begin{array}{l}\text { Avoid shadows } \\
\text { and patterned } \\
\text { surfaces; } \\
\text { provision of } \\
\text { edge strips }\end{array}$ & $\begin{array}{l}\text { Avoid patterned surfaces; } \\
\text { Automatic lighting control } \\
\text { is highly recommended, } \\
\text { time delay switches are not } \\
\text { suitable }\end{array}$ & $\begin{array}{l}\text { Carefully positioned } \\
\text { lighting can be used } \\
\text { to highlight steps, } \\
\text { nosings and other } \\
\text { hazards }\end{array}$ \\
\hline
\end{tabular}

Table 1 - Overview of lighting specifications for stairs in different documents.

Good staircase lighting is not the only requisite to achieve good stair visibility. Using contrast strips on stair noses can increase the contrast between the stair noise and the background, which can reduce fall accidents if properly designed. Especially for elderly and people with impaired vision [19].

Despite these guidelines, it remains difficult to specify exactly what is needed for good stair lighting: sufficient illuminance and good uniformity with limited or no shadows but at the same time providing sufficient contrast to highlight steps and other hazards. Integrating lighting in the staircase can increase the contrast and visibility. However, glare should be avoided which can be challenging due to the difference in height and the variations in viewing angle. Preferred stair lighting can also vary over time, such as the preference for dim lighting at night. Therefore, because of its dependence on many parameters, defining a good staircase lighting design remains challenging.

Contrast between the steps of the stairs is one of the most important lighting specification, as indicated by the results of the exploratory studies and recommendations of the lighting specifications. While the lighting specifications report recommend illuminance ranges and maximum luminance values to avoid glare, it is no guarantee to achieve adequate contrast, especially for light sources integrated within the stair design.

The goal of the presented research is to get more insight in how the (sense of) safety of a home environment can be improved by an intelligent stair design: what type of integrated lighting groups at which luminous intensity and what colour of steps are preferred to create a safe staircase situation for elderly in a night-time setting.

\section{METHODOLOGY}

\subsection{Experimental setup}

The experiment was carried out on the premises of 'Happy Aging', a non-profit organization that regularly performs practical tests or surveys with older people. The mock-up staircase was placed in a hall with a stairwell (Figure 1 on the right). The stairs of the original stairwell were covered with black cloths. The structure of the demountable, wooden staircase is shown in Figure 1 on the left, and 
consists of a wooden frame with a wooden handrail and five separate wooden, detachable steps. Each step had a rise of approximately $17 \mathrm{~cm}$ and a going of $\sim 28 \mathrm{~cm}$. These values are well within acceptable criteria considering stair geometry [5]. Each step was covered with an interchangeable magnetic cover made of a light- or dark-brown wooden texture (see Figure 2). The staircase had a total of five individually adjustable luminaire groups. A LED strip (OSRAM LEDs Deco Flex Base) was built inside the handrail, illuminating the staircase. Each step had two LED strips built in the stair nose, one mounted upwards (LED-profile: Unibright S-line Corner) and one downwards (LED-profile: Unibright S-line Low). During the experiment, a lighting scene consisted of one or two of the aforementioned luminaire groups. The final two luminaire groups consisted of seven spotlights built inside the main wooden frame, two (DeltaLight HELI 1 Screen LED WW) illuminating the whole staircase and five (DeltaLight HELI 1 LED WW) illuminating each step individually. Both luminaire groups were not investigated, although were used as global illumination before the experiment and during breaks. The only active light sources in the stairwell were the luminaire groups of the mock-up stairs as the roof dome was covered and other light sources were switched off. Observers stood upright on the platform of the stairwell in front of the mock-up staircase with a top-to-bottom view (Figure 1 on the right, position of the tripod). The structure of the mock-up staircase was not rigid enough to allow observers to ascend or descend the stairs. During breaks, observers could rest on a chair covered with a grey cloth, placed at the back of the platform. Each luminaire group was separately controllable with a 0-10 V dimmer (SR-2002), directly connected to an analog voltage output generator with 16-bit resolution (USB-3103). The experiment was programmed in MATLAB R2017b to control the analog voltage output device, allowing for adjustments to the luminous intensity of each individual luminaire group. Two experiment supervisors helped during the experiment. One supervisor sat below the staircase platform in a corner out of sight of the observer, and controlled the software and registered observer input. The other supervisor stood next to the observer for safety measures and explained instructions verbally to the observer during the experiment.
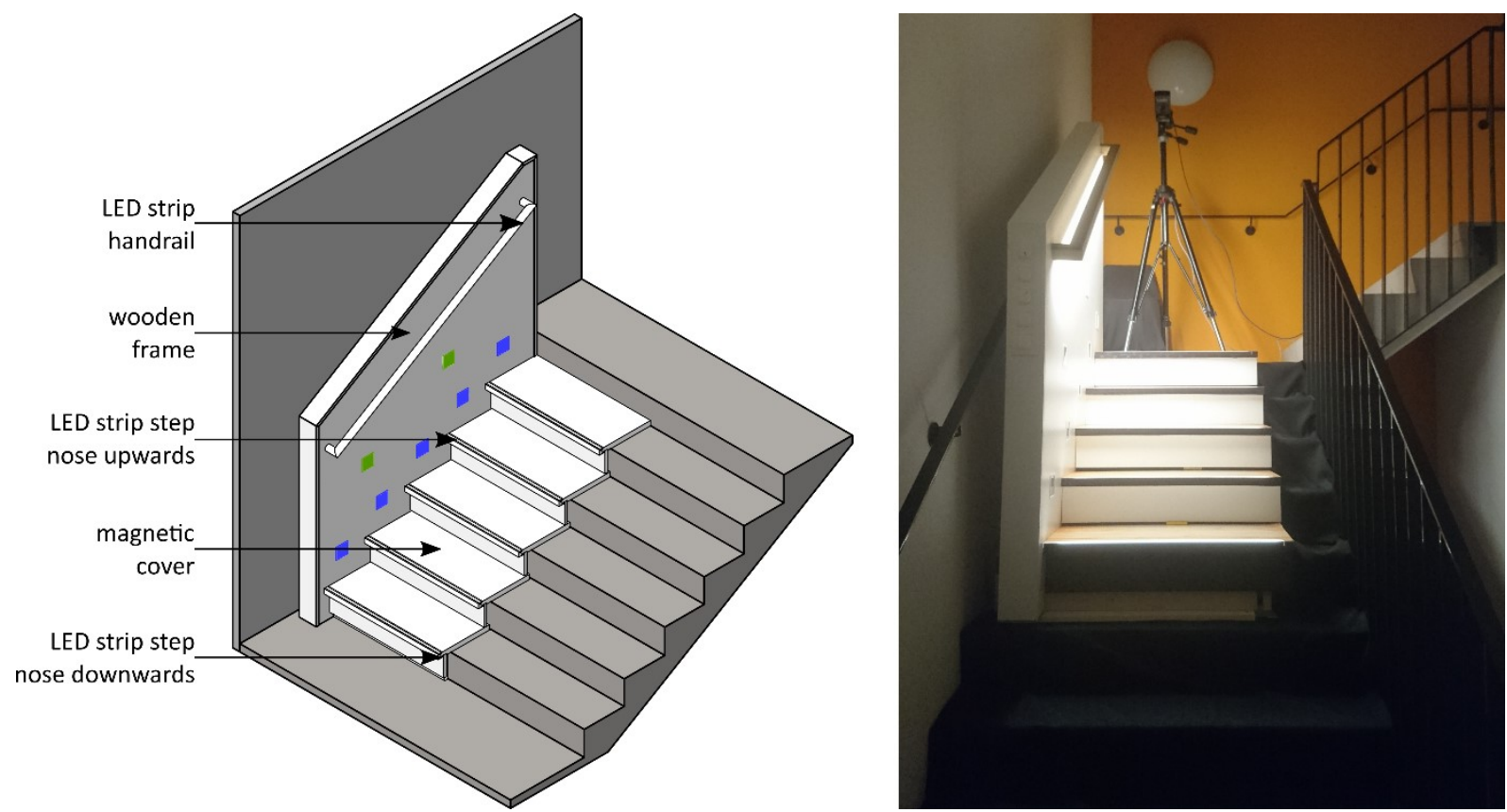

Figure 1 - Left: Structure of the moveable mock-up staircase. The green squares denote the spots illuminating the whole staircase and the blue squares are the spots that illuminate each step individually. Right: Bottom-up view of the mock-up staircase in the stairwell with a luminance camera mounted on a tripod at the observer position.

\subsection{Procedure}

Observers were asked to assess different lighting scenes in terms of the perceived safety of descending a staircase. Although no specific definition for their perceived safety of descending a stair was given, 
observers were informed to consider among others the degree of glare, depth perception and contrast of a step and contrast between steps. The three investigated luminaire groups are referred as the (hand) rail LED strip, the LED strips under and on the stair nose. The latter two are also referred as the downward or upward LED strips, respectively. A lighting scene consists of one or a combination of two luminaire groups, e.g. handrail LED strip and/or upward LED strips. During the experiment, observers stood in front of the stairs on a platform and were advised to focus on the middle of the mock-up stairs when evaluating the lighting scenes. This is around the $3^{\text {rd }}$ step (with the $1^{\text {st }}$ step being the highest), which is most commonly the step where an average observer is focussed at during stair descent [20]. Two types of stair colours for the magnetic covers were used, a light- or dark-brown wooden texture, both in a matte finish (Figure 2). Spectral reflectance curves of both covers were measured using a spectrophotometer (Hunterlab UltraScan PRO). The obtained reflection coefficients $\left(\rho_{D 65}\right)$ were approximate $68 \%$ and $24 \%$ for the light- and dark-brown wooden cover, respectively, using $\mathrm{ClE}$ Standard Illuminant D65 as reference source.

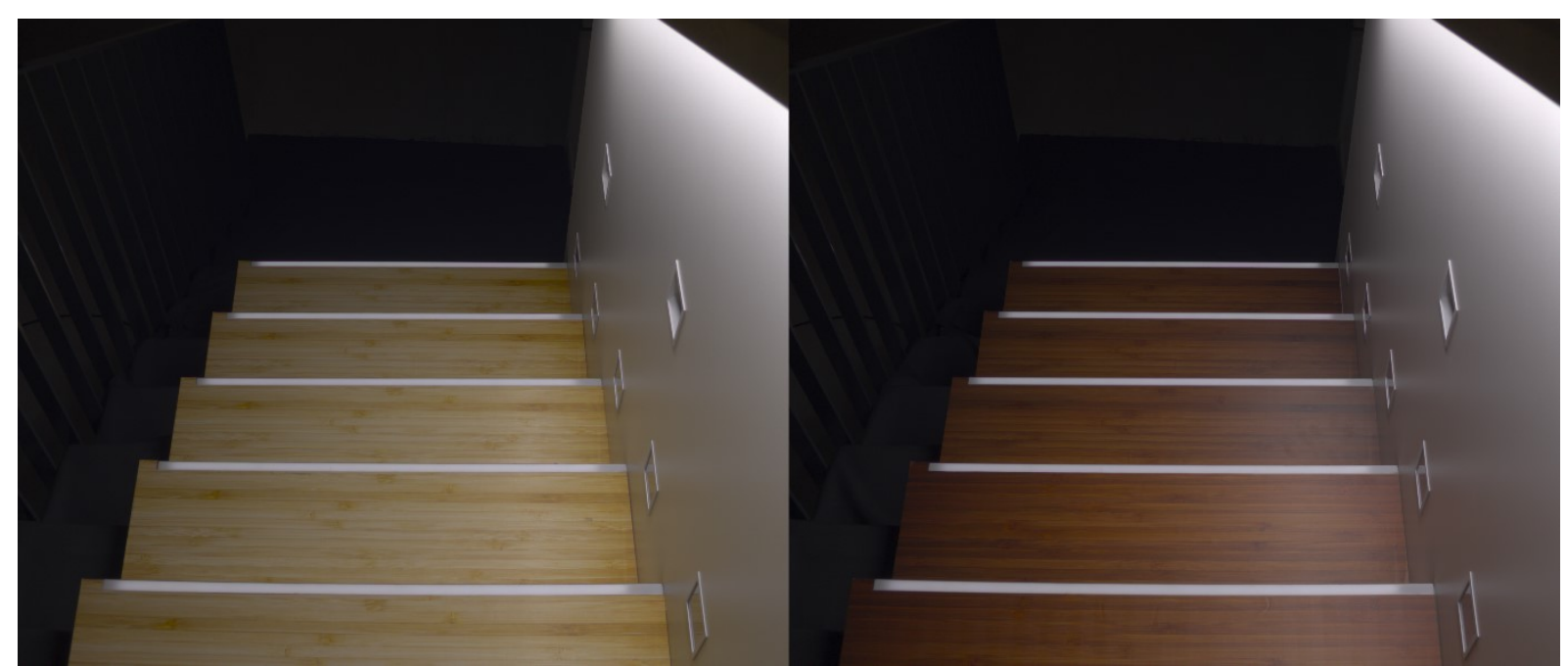

Figure 2 - Images captured from the observer point of view using a luminance camera. The light- and dark-brown wooden covers are shown on the left and right, respectively. The images depict a lighting scene where the LED strip handrail was fully lit and the upwards LED strip build in the step nose was partially lit.

Observers filled in a questionnaire before the start of the experiment. The questionnaire consisted of general information of the observer (name, age, gender and height), information regarding their vision (visual acuity, colour vision deficiency, eye defects, type of glasses/contact lens) and information regarding staircases (type of staircase at home, previous fall related incidents on staircases and preferred staircase lighting).

Two experiment parts were conducted for each colour of the stair cover (light- and dark-brown), investigating perceived safety of descending a staircase. The first part required observers to set the preferred average luminous intensity of several luminaire groups. In the second part, observers scored several lighting scenes using a rating scale. Each observer started with a random stair colour and completed both parts, followed by a mandatory break of approximately five minutes. During the break, the experiment supervisor controlling the software changed the magnetic covers on the steps, while the other supervisor gave further instructions to the observer. After the break, both parts were repeated with the newly changed stair colour. After the experiment was completed, observers could give additional feedback.

\subsubsection{Part one: preferred average brightness}

In the first part, the observers were shown four lighting scenes in which the luminaire group(s) gradually increased, respectively decreased in luminous intensity. The four lighting scenes consisted of: 1) the upward LED strips separately; 2) the handrail and upward LED strips combined; 3 ) the 
downward and upward LED strips combined; and 4) the downward LED strips separately. The second and third lighting scenes had a fixed upward LED strip intensity obtained from the first lighting scene. Initially, the intensity gradually increased for a total of 10 seconds until fully lit. This was repeated and observers indicated their preferred luminous intensity considering stair safety. Afterwards, this process was repeated but now starting from a fully lit luminaire group that was gradually dimmed. Upon request, observers could see the gradual increase/decrease again. The mean of the preferred increasing and decreasing luminaire group setting (voltage output to the dimmer, directly related to the luminous intensity of the light source) were calculated. This resulted in a preferred average voltage output of each luminaire group for each lighting scene.

\subsubsection{Part two: rating perceived safety}

In the second part, several lighting scenes were shown in a random order for each observer. Each scene was scored on the perceived safety of descending a stair, with a categorical number from 0 to 10 , where 0 is totally unacceptable (e.g. dark), 10 is perfect and 5 the limit of barely adequate lighting to descend the stairs in a safe manner. A lighting scene consisted of either a single individual luminaire group or a combination of two luminaire groups. Each of the three individual luminaire groups (LED strip handrail, LED strip in stair noise upward or downward) was shown with four brightness levels with a voltage output of $2.5 \mathrm{~V} ; 5 \mathrm{~V} ; 7.5 \mathrm{~V}$ and $10 \mathrm{~V}$ to the driver, respectively. This resulted in 12 lighting scenes for all individual luminaire groups.

Additionally, two combinations of luminaire groups were investigated: the handrail \& upward LED strips; and the downward \& upward LED strips. A combination of two luminaire groups resulted in a total of 16 lighting scenes, using the same four brightness levels as the individual luminaire groups. This resulted in a total of 32 lighting scenes for both combinations of luminaire groups.

Furthermore, 5 repeated lighting scenes were shown to the observers, two from the individual luminaire groups and three from the combined luminaire groups, randomly chosen for all observers. A dark scene (no active light sources) was also presented to the observers along with the 4 lighting scenes individually obtained per observer from the first part. In total 54 lighting scenes $(12+32+5+1+4)$ per stair cover were shown to each observer in random order to counter balance order effect and without an imposed time limit. Upon request observers could see a lighting scene again. Observers were sporadically informed of how many lighting scenes were scored but no information was given regarding the type of lighting scene shown (combination of luminaire groups or brightness levels).

\subsection{Measurements of lighting scenes}

In order to gain a better understanding of how lighting influences safety perception when descending a stair, all lighting scenes were measured using a colorimetric imaging camera (Techno Team LMK5-5 Color). The measured output is a tristimulus image (XYZ map) in CIE XYZ color space (1931 $2^{\circ}$ observer). In this way, the luminance ( $Y$-value) at each pixel in an image of a lighting scene is obtained. For each observer, the 8 individually obtained lighting scenes (4 per stair cover) were measured. The lighting scenes in part two were also measured, resulting in $100 \mathrm{XYZ}$ maps (50 per stair cover). Based on the measured $X Y Z$ maps, on average, the peak luminance values of the upwards LED strips were approximately $55 \mathrm{~cd} / \mathrm{m}^{2}, 480 \mathrm{~cd} / \mathrm{m}^{2}, 2600 \mathrm{~cd} / \mathrm{m}^{2}$ and $8400 \mathrm{~cd} / \mathrm{m}^{2}$ for the brightness levels $2.5 \mathrm{~V}, 5 \mathrm{~V}$, $7.5 \mathrm{~V}$ and $10 \mathrm{~V}$, respectively. These luminance values were similar for the two other investigated luminaire groups since the same LED strips were used. Each XYZ map was divided in several regions of interest (ROI). For each of the steps two regions were selected, one corresponds with the upward LED strip and the other with the stair cover. Figure 3 shows the ROI for the middle step. Per region of interest several features were calculated such as the average, maximum and minimum luminance. These features can be used to create a model to accurately predict the observer estimations. 


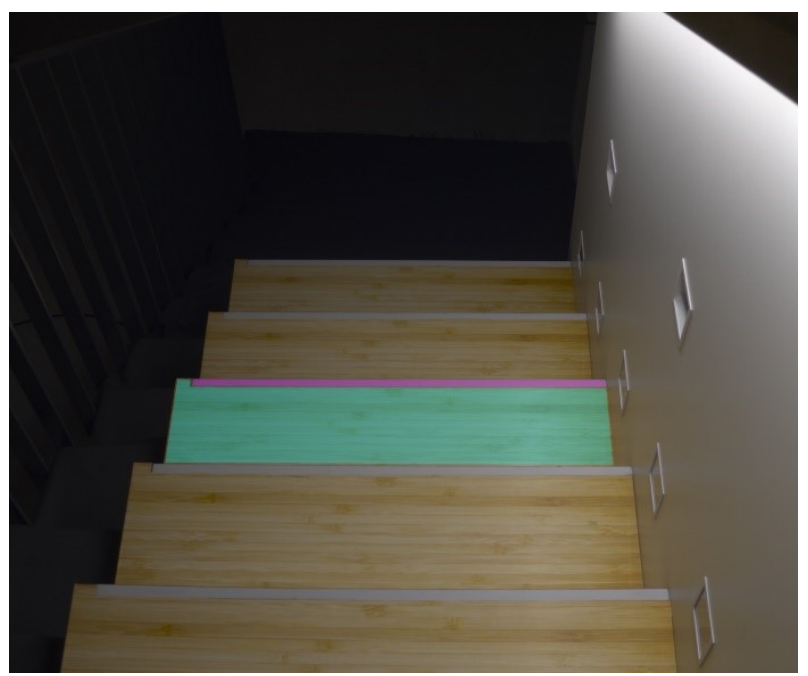

Figure 3 - Image captured from the observer point of view using the luminance camera. A lighting scene is shown where the LED strip handrail was fully lit and when using a light-brown cover. The ROls of the middle step for the upward LED strip and the stair cover is shown in magenta and cyan, respectively.

\section{RESULTS}

Thirty observers - 15 women and 15 men - with ages ranging from 59 to 88 years old (average 72.9 years old) took part in the study. All observers were recruited via Happy Aging and were randomly selected from the organisation's database of elderly volunteers. In exchange for their participation, all received a theatre gift voucher and a box of chocolates. All observers reported to have normal (corrected) visual acuity, no colour vision deficiency and no current eye defects. Six randomly assigned observers were asked to return at a later date and complete the experiment a second time to analyse the test-retest reliability. There were approximately five to six days between both experiments for each of the six observers.

\subsection{Part one: preferred lighting settings}

The results of the four lighting scenes in part one are subdivided by individual (lighting scene 1 \& 4) and combined luminaire groups (lighting scene $2 \& 3$ ).

\subsubsection{Lighting scenes with individual luminaire groups}

Figure 4 shows the preferred luminaire group settings as voltage output for the LED strips facing upward and downward separately. The voltage outputs of the upward LED strip with the light-brown cover had a mean $(M)$ of 6.88 , standard error $(S E)$ of 0.30 with a gradual increase $(\lambda)$ in luminous intensity and $M=6.88, S E=0.18$ with a gradual decrease $(\searrow)$. A paired samples $t$-test showed no significant $(p \leq 0.05)$ difference in voltage outputs between the gradual increase and decrease of luminous intensity $(t(29)=0.020, p=0.984)$. The voltage outputs with the dark-brown cover between gradual increase $(M=6.61, S E=0.36)$ and decrease $(M=6.45, S E=0.26)$ also showed no significant difference $(t(29)=0.629, p=0.535)$.

However, on average the voltage output of the downward LED strip with the light-brown cover was significantly lower when a gradual increase $(M=7.30, S E=0.37)$ is compared to a gradual decrease $(M=8.01, S E=0.29)$ in luminous intensity $(t(29)=-2.999, p=0.006)$. The voltage outputs with the dark-brown cover between gradual increase $(M=7.29, S E=0.34)$ and decrease $(M=7.80, S E=0.30)$ also showed a significant difference $(t(29)=-2.513, p=0.018)$.

This indicates that an anchor effect is present, a gradual increase in luminous intensity led to lower adjusted values compared to a gradual decrease. Therefore, the mean of both adjustments is used to counterbalance this effect, resulting in a preferred luminous intensity (average voltage output) for each luminaire group. 
For the upward LED strip, the observers set, on average, a higher mean voltage output with a lightbrown cover $(M=6.88, S E=0.22)$ compared to a dark-brown cover $(M=6.53, S E=0.29)$, although this difference was not significant $(t(29)=1.779, p=0.086)$. Similarly, for the downward LED strip the lightbrown cover ( $M=7.66, S E=0.31)$ had higher adjusted mean voltage outputs compared to the darkbrown cover $(M=7.55, S E=0.31)$, but this difference was also not significant $(t(29)=0.658, p=0.516)$.
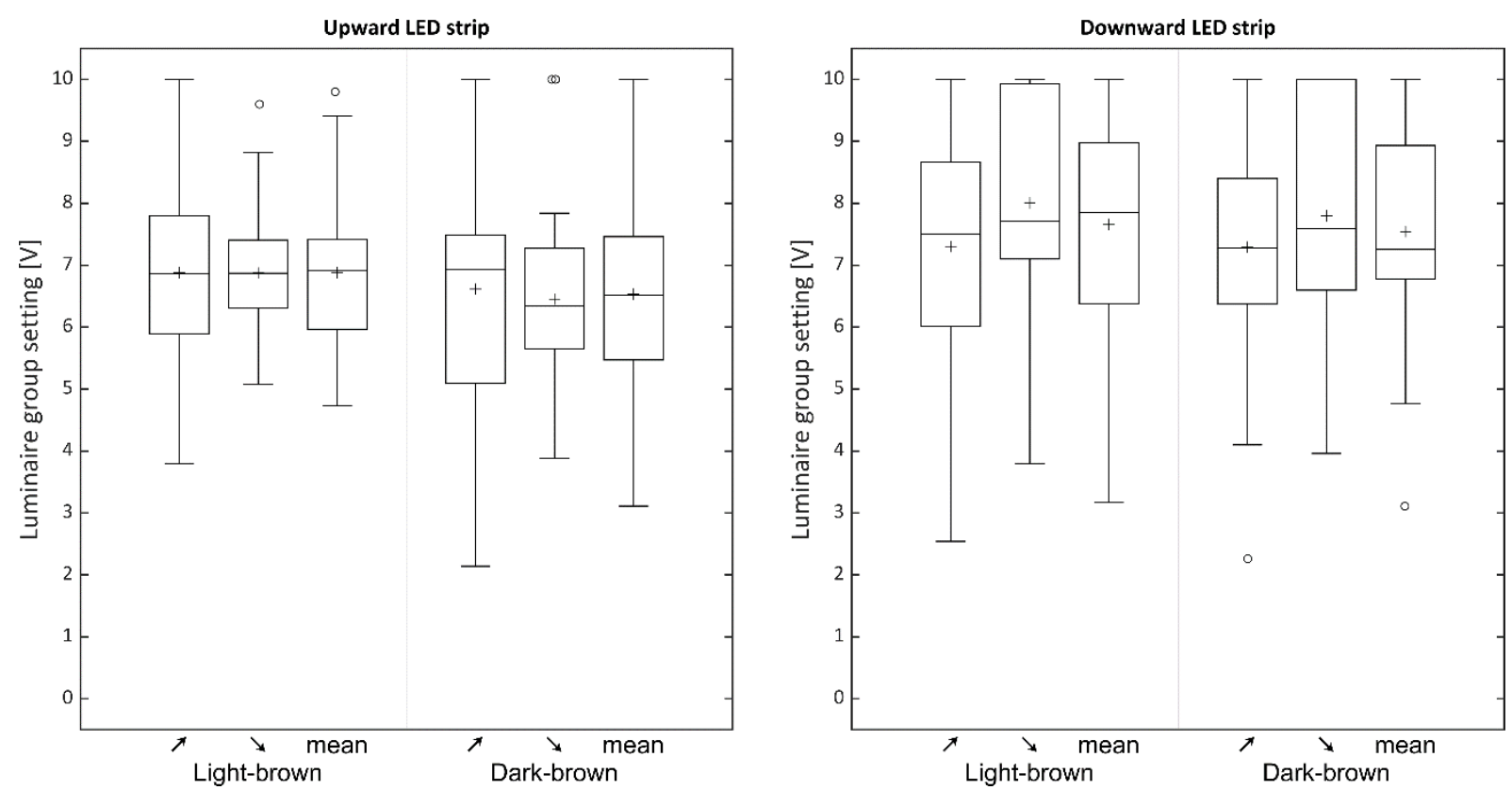

Figure 4- The adjusted luminaire group settings for the upward and downward LED strips are shown on the left and right, respectively. The light- and dark-brown wooden cover subdivides the results of each luminaire group. Per wooden cover, a boxplot is shown for the adjusted luminaire setting in case of gradual increase $(\lambda)$ or decrease $(\searrow)$ of the luminous intensity and the average of both (mean). Each boxplot represents the adjusted voltage output [V] of all observers, the mean is shown as a ' + ' and the median is a horizontal solid black line. Outliers are shown as an ' 0 '.

Based from previous results, one could conclude that the difference of the preferred luminous intensity between the light- and dark-brown wooden cover is insignificant for both the upward and downward LED strip. In a next step, the luminance distribution of the scenes (luminance maps) - which are more related to what observers perceive - are compared. From observers' feedback, the difference in brightness between the upward LED strip and the wooden cover plays an important role in adjusting the preferred luminous intensity. As observers were instructed to focus around the middle of the stairs, the average luminance of both the wooden cover and upward LED strip were calculated for the middle step.

On average, for the preferred adjusted downward LED strip scene, the observers set a higher average luminance on the wooden cover for light-brown $\left(M=37.15 \mathrm{~cd} / \mathrm{m}^{2}, S E=5.03\right)$ compared to a darkbrown cover $\left(M=7.36 \mathrm{~cd} / \mathrm{m}^{2}, S E=1.06\right)$. This difference was significant $(t(29)=7.014, p \leq 0.001)$. This is expected since the reflection coefficient of the light-brown cover is higher than the dark-brown cover and the difference between the wooden covers of the adjusted mean voltage was not significant for the downward LED strip scene.

On average, for the preferred adjusted upward LED strip scene, a higher average luminance on the upward LED strip was found when a light-brown cover was used $\left(M=1771.64 \mathrm{~cd} / \mathrm{m}^{2}, S E=298.46\right)$ compared to using a dark-brown cover $\left(M=1543.45 \mathrm{~cd} / \mathrm{m}^{2}, S E=282.30\right)$. This difference was not significant $(t(29)=1.347, p=0.188)$, indicating that the adjusted average luminance of the upward LED strip was independent of type of wooden cover used. This is expected as the upward LED strip emits no direct light towards the wooden covers. Observers' feedback showed that the use of only the upward LED strips was an inadequate lighting scene to safely descend the stairs, because the steps themselves were perceived as less visible. This is also confirmed by the individual ratings the observers 
gave in part two for their adjusted upward LED strip scene. On average, observers scored their own adjusted scene a 2.90 and 2.50 for the light- and dark-brown, respectively. This difference between covers was not significant $(t(29)=1.263, p=0.216)$. Observers' feedback and the rating from part two show that observers preferred their adjusted downward LED strip scene. On average, observers scored their own adjusted scene a 7.80 and 7.67 for the light- and dark-brown, respectively. This difference was also not significant $(t(29)=0.436, p=0.666)$.

\subsubsection{Lighting scenes with combined luminaire groups}

Previous results discussed the two lighting scenes with the individual luminaire groups using the adjusted voltage output and the average luminance of the upward LED strip and wooden cover of the middle step. The average luminance values were also used to describe the two other lighting scenes. Both lighting scenes $(2 \& 3)$ are each a combination of two luminaire groups: the upward \& handrail LED strips combined, and the upward \& downward LED strips combined, respectively. Figure 5 shows for both scenes the average luminance of the upward LED strip and wooden cover of each observer's preferred luminaire group setting.

Each observer adjusted the luminous intensity of the upward LED strip separately (in part 1), resulting in average luminance values of the upward LED strip between approximately 175 and $6450 \mathrm{~cd} / \mathrm{m}^{2}$, with a mean of $1172 \mathrm{~cd} / \mathrm{m}^{2}$ for the light-brown cover. The data are shown in the left graph of Figure 5 . As the observers set a higher intensity of the upward LED strip, the observers' adjusted intensity of either the downward or handrail LED strip increased, resulting in an increasing average luminance of the wooden cover. This result is also in accordance with observers' feedback: as the brightness of the upward LED strip increases, more light is needed on the wooden cover to distinguish each step. Pearson correlation coefficients $(r)$ were calculated between the average luminance of the upward LED strip and the light-brown wooden cover. Results were highly correlated, $r=0.84$ for the combined handrail and upward LED strips scene (filled circles) and $\mathrm{r}=0.79$ for the combined upward and downward LED strips scene (downward triangles). Figure 5 also shows that $90 \%$ of the observers needed a higher average luminance on the light-brown wooden cover with the upward and downward LED strip scene compared to the upward and handrail LED strip scene.

When comparing the wooden covers, the average luminance of the wooden cover for the light-brown was higher compared to that of the dark-brown cover, maximum average luminance values were around 100 and $30 \mathrm{~cd} / \mathrm{m}^{2}$, respectively. The results found for the light-brown wooden cover were similar to the results of the dark-brown wooden cover.

Average luminance values of the upward LED strip for the dark-brown cover, shown right in Figure 5, were approximately between 45 and $6250 \mathrm{~cd} / \mathrm{m}^{2}$ with a mean of $1543 \mathrm{~cd} / \mathrm{m}^{2}$. Pearson correlation coefficients between the average luminance of the upward LED strip and the dark-brown wooden cover were $r=0.86$ for the combined handrail and upward LED strips scene, and $r=0.81$ for the combined upward and downward LED strips scene. In total $80 \%$ of the observers had a higher average luminance on the dark-brown wooden cover with the upward and downward LED strip scene compared to the upward and handrail LED strip scene. 

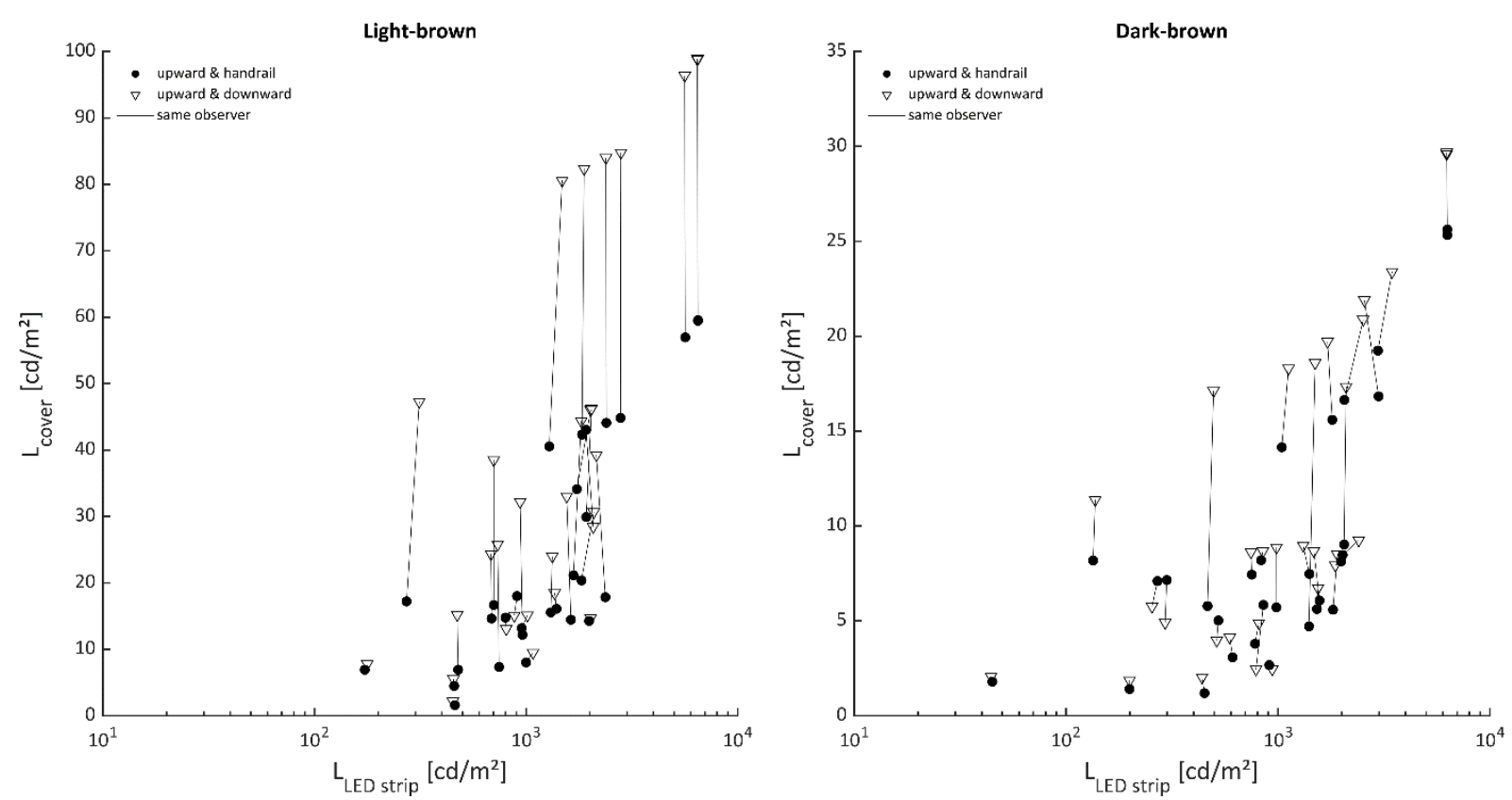

Figure 5 - The average luminance of the upward LED strip and wooden cover of each observer's preferred luminaire group setting are shown. The average luminance values with the light- and dark-brown cover are shown on the left and right side, respectively. The scene with the combination of upward and handrail LED strips is shown as a filled circle and the scene with the combination of upward and downward LED strips is shown as a downward triangle. A line between these markers denote the preferred luminaire group settings for a single observer.

The observers' ratings from part two for the adjusted scene with upward and handrail LED strips combined had an average rating of 5.00 and 4.60 for the light- and dark-brown cover, respectively. This difference was not significant $(t(29)=0.993, p=0.329)$. The ratings for the adjusted scene with the upward and downward LED strips combined had an average rating of 6.10 and 5.70 for the lightand dark-brown cover, respectively. This difference was also not significant $(t(29)=1.090, p=0.285)$. When comparing the ratings between both adjusted scenes (upward \& handrail and upward \& downward) for each cover, a significant difference was found for the light-brown $(t(29)=-3.657$, $p=0.001)$ and dark-brown $(t(29)=-2.387, p=0.024)$ cover. This indicates that when observers adjust the luminous intensity of the handrail or downward LED strip in combination with a preferred luminous intensity of the upward LED strips, observers prefer the scene with the upward and downward LED strips for stair safety descent, assuming that observers set their preferred luminous intensity. A possible explanation could be that a higher average luminance on the wooden covers is obtainable with the downward LED strip compared to the handrail LED strip, and more light is needed to compensate for the upward LED strip intensity.

\subsection{Part two: rating stair safety}

\subsubsection{Reliability measure}

The Intraclass Correlation Coefficient (ICC) is used to check observer reliability [21]. ICC values range between 0 and 1 , with values closer to 1 representing stronger reliability. ICC values less than 0.5 , between 0.5 and 0.75 , between 0.75 and 0.9 , and greater than 0.9 are commonly indicated as poor, moderate, good and excellent reliability, respectively [22]. The method proposed by [22, 23] is used as a guideline to select the appropriate ICC form.

The test-retest reliability is calculated for each of the six observers who completed the experiment twice on different days. ICC estimates and their $95 \%$ confidence intervals (C.I.) were calculated using MATLAB based on a single-rater, absolute-agreement, two-way mixed effects model. The average ICC was 0.803 . Based on the C.I. of the average ICC, five observers had a test-retest reliability of moderateto-good and one observer had good-to-excellent. The mean absolute difference of the ratings per 
observer is also calculated as an extra metric [24], the average for the six observers was 1.215. The results indicate that the six observers gave consistent results between repeated experiments.

The intra-observer reliability was evaluated similarly to the test-retest reliability, using a single-rater, absolute-agreement, two-way mixed effects model. The 10 repeated lighting scenes ( 5 per wooden cover) scores were used per observer. Based on the C.I. of the estimated ICCs of each observer, one observer had a reliability of poor-to-moderate, 7 poor-to-good, 5 moderate-to-excellent, 16 poor-toexcellent and one excellent. The average ICC was 0.717 . These results are substantially lower compared to the test-retest reliability ICC (0.803). This could reflect a lower degree of observer agreement and/or could be due to the limited number of repeated lighting scenes used [22]. However, the mean absolute difference averaged for all 30 observers was 1.247 , similar to the test-retest value, indicating that the lower ICCs were likely due to the small number of repeated lighting scenes used.

The inter-observer reliability was evaluated by calculating the ICC based on a multiple-rater, absoluteagreement, two-way mixed effects model for the 30 observers and 100 scenes (45 unique and 5 repeats for both wooden covers, excluding the four individual lighting scenes from part one). The obtained ICC was 0.978 , its $95 \%$ C.I. ranged between 0.971 and 0.984 , indicating an excellent level of reliability. This indicates that observers responded consistent with each other and the average observer (pooling the data of all the observers) is a good representation of the data.

\subsubsection{Observer scores}

The observer scores from part two are presented for the combination of upward \& downward luminaire groups followed by the upward \& handrail luminaire groups. Afterwards the results are analysed on significance of effects using a linear mixed model.

\subsubsection{Upward and downward luminaire groups}

Figure 6 shows the observers scores as boxplots categorized per scene with a combination of the upward and downward LED strip luminaire groups. The scores of the adjusted scenes from part one for the individual observers are not shown. The horizontal axes depict the voltage output of the downward and upward LED strips, which is directly related to the luminous intensity of the luminaire groups. Based on Figure 6 several effects are clearly visible. The scenes with the individual upward luminaire group (first column of boxplots) shows a very low overall score for any intensity and for both covers, with, on average, scores below three. As the intensity of the upward LED strips increases, the score generally decreases (seen per column, groups of boxplot). However, when the intensity of the downward LED strips increases, the score increases. When the downward luminaire group is fully lit (down $=10 \mathrm{~V}$ ), the scores between the upward intensity at $0 \mathrm{~V}$ and $2.5 \mathrm{~V}$ are almost equal. This indicated that a slight increase of upward luminous intensity does not necessarily always result in an unacceptable lighting scene. Observer feedback indicated that a dim upward LED strip could increase contrast and could sometimes lead to a more preferred lighting scene. However, the amount of upward luminous intensity is crucial as too much light can rapidly cause discomfort (glare). Comparing both covers indicate, on average, a marginally higher score for the light-brown cover. 

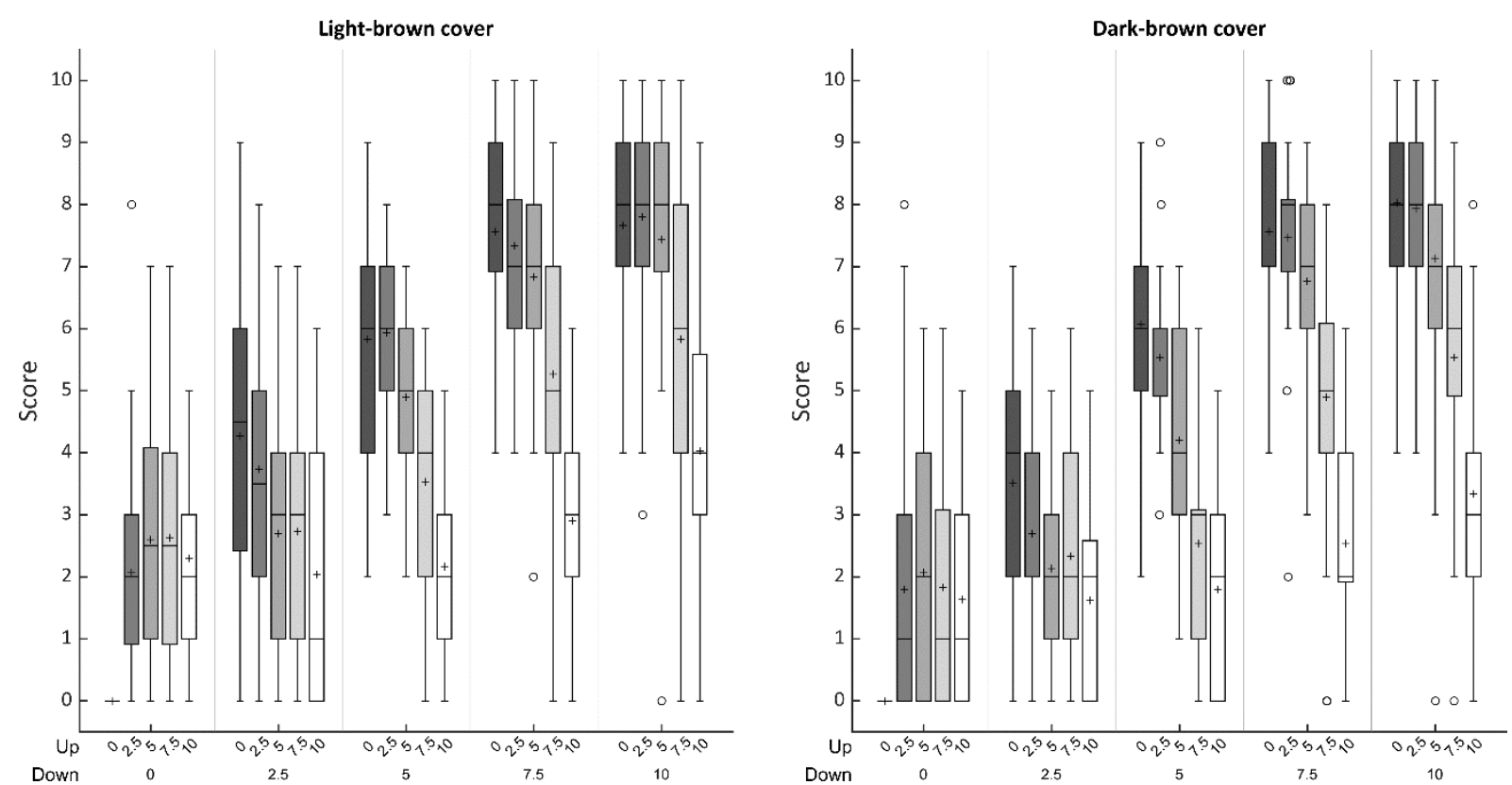

Figure 6 - Observers scores shown as boxplots for the lighting scenes with the upward and downward LED strips. The lightand dark-brown wooden covers on the left and right, respectively subdivide the results. The horizontal axes denote the dimming values for the downward ('Down') and upward ('Up') LED strips. Per boxplot, the mean is shown as a ' + ' and the median is a horizontal solid black line. Outliers are shown as an ' $o$ '.

\subsubsection{Upward and handrail luminaire groups}

Figure 7 shows the observers scores as boxplots categorized per score with a combination of the upward and handrail LED strip luminaire groups. Note that the scores of the individual upward luminaire group (first column of boxplots) is the same as in Figure 6. Based on Figure 7 several effects are clearly visible. As the intensity increases of the upward LED strips, the score generally decreases (seen per column, groups of boxplot). Whereas when the intensity of the handrail LED strip increases the score generally increases. Similar to the results of the upward \& downward luminaire groups the light-brown cover had, on average, a marginally higher score compared to the dark-brown cover for the upward and handrail luminaire groups.
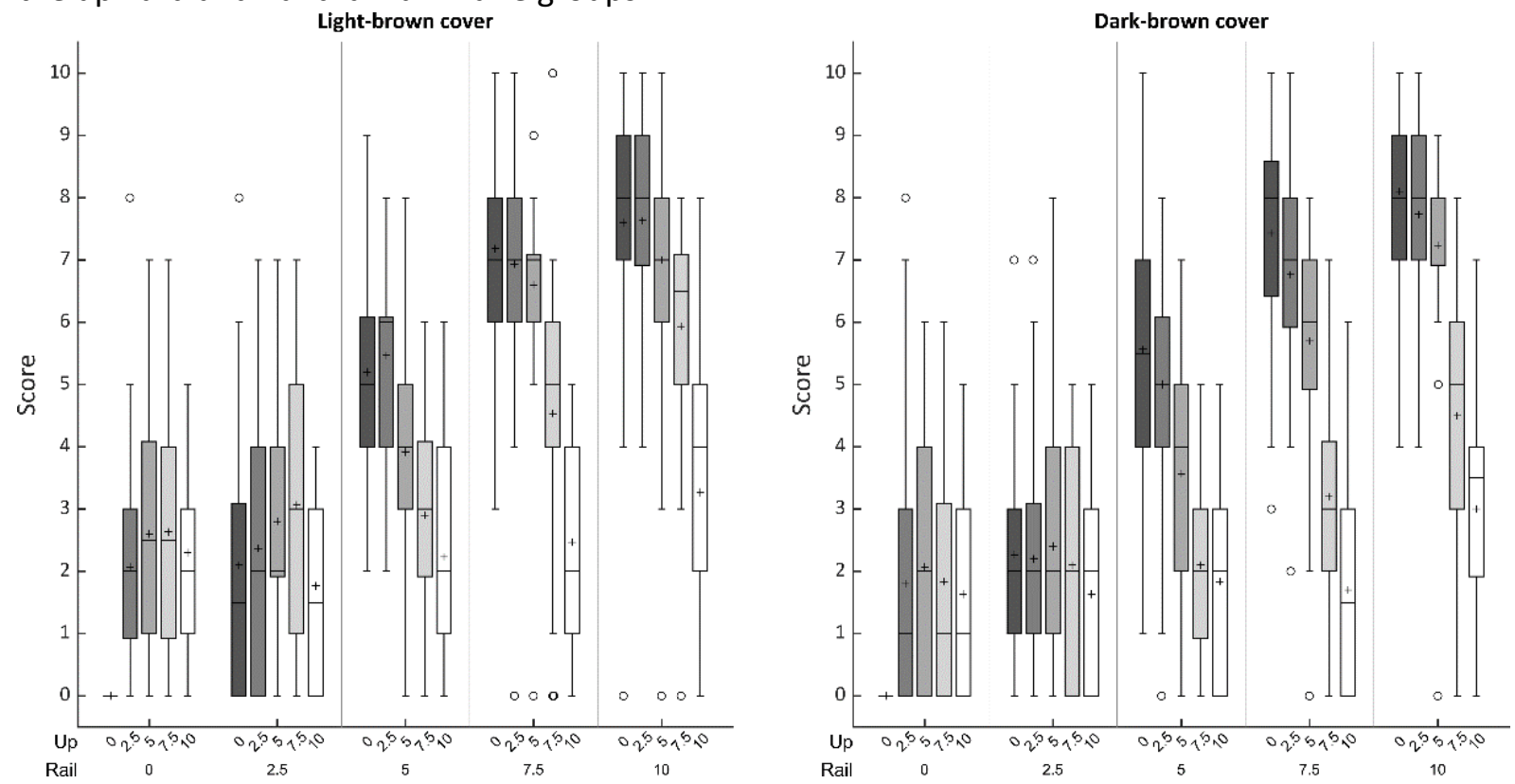

Figure 7 - Observers scores shown as boxplots for the lighting scenes with the upward and handrail LED strips. The lightand dark-brown wooden covers on the left and right, respectively subdivide the results. The horizontal axes denote the dimming values for the handrail ('Rail') and upward ('Up') LED strips. Per boxplot, the mean is shown as a ' + ' and the median is a horizontal solid black line. Outliers are shown as an ' 0 '. 
Comparing the average scores between the upward \& handrail (4.375) and upward \& downward (4.853) luminaire groups shows that marginally higher score were obtained with the latter. A possible explanation could be that the downward LED strip can compensate more for the high luminous intensities of the upward LED strip. When comparing the scores between the downward and handrail individual luminaire groups at maximum luminous intensity - which were one of the highest scored scenes - no significant difference were found when using either the light-brown $(t(29)=0.235$, $p=0.816)$ or dark-brown $(t(29)=-0.284, p=0.778)$ covers.

\subsubsection{Linear mixed model}

The $R$ language [25] and package Ime4 [26] has been used to perform a linear mixed-effects model (LMM) analysis on the observer scores. Restricted maximum likelihood was used as estimation method for the model. The fixed effects in the model included the cover type with the upward \& downward luminaire groups (with interaction terms) and the cover type with the upward \& rail luminaire groups (with interaction terms). All fixed effects were considered as categorical. Each observer had an intercept as only random effect. Visual inspection of residual plots did not reveal any deviations from homoscedasticity or normality. The random intercepts were tested on normality using Shapiro-Wilk's method and normality was assumed ( $p=0.635)$. Significance of fixed effects was tested using the Wald Chisquare test (Table 2).

The light-brown cover results in higher average luminance values and has a slightly higher average score (4.45) compared to the dark-brown cover (4.09), although this effect was not significant. The main effects of the luminaire groups were as expected significant. Increasing the intensity of the upward luminaire groups generally leads to a decrease in score whereas increasing the intensity of the downward or handrail luminaire group generally increased the score. The type of cover used did not significantly affect the observer scores for each individual luminaire group. A significant interaction effect was found between the upward \& downward luminaire groups and between the upward \& handrail luminaire groups. This is expected, if the intensity of the upward luminaire group increases, the downward or handrail luminaire group intensity needs to increase to achieve a similar or better result, because more light is needed to compensate the high upward luminous intensity. This effect was also found in part one. When the upward intensity is too high, the visibility between the steps decreases, resulting in a lower score. Both three-way interaction effects were not significant, indicating that the cover had no significant impact on score given the voltage outputs of either the upward \& downward and upward \& handrail luminaire groups.

\begin{tabular}{l|r|r|r} 
& \multicolumn{1}{|c|}{$\chi^{2}$} & Dof & \multicolumn{1}{c}{$\boldsymbol{p}$} \\
\hline Cover & 3.673 & 1 & 0.055 \\
\hline Up & 524.394 & 4 & $<0.001$ \\
Down & 985.523 & 4 & $<0.001$ \\
Rail & 908.183 & 4 & $<0.001$ \\
\hline Cover : up & 5.372 & 4 & 0.251 \\
Cover : down & 6.321 & 4 & 0.176 \\
Cover : rail & 3.180 & 4 & 0.528 \\
\hline Up : down & 262.842 & 16 & $<0.001$ \\
Up : rail & 312.869 & 16 & $<0.001$ \\
\hline Cover : up : down & 11.983 & 16 & 0.745 \\
Cover : up : rail & 7.229 & 16 & 0.969 \\
\hline
\end{tabular}

Table 2 - Results of Wald Chisquare test for fixed effects. The columns show from left to right: the fixed effect, Chisquare value, degree of freedom (Dof) and the $p$-value.

\subsubsection{Luminance model}

The results in part one indicated that the average luminance of the upward LED strip and wooden cover plays an important role in assessing the preferred luminous intensity regarding stair safety. A model has been fitted using the average luminance values of the upward LED strip and of the wooden cover 
of the middle step as predictor variables. The scores of the average observer data from part two were used as outcome variable. The model is implemented as a sigmoidal function.

$$
\hat{S}=K \frac{L_{\text {cover }}{ }^{n}}{L_{\text {cover }}{ }^{n}+\left(c+\frac{L_{\text {strip }}}{c 1}\right)}
$$

$\operatorname{In}(1), \hat{S}$ is the predicted observer score for a stairway scene with $L_{\text {cover }}$ the average luminance of the wooden cover and $L_{\text {strip }}$ the average luminance of the upward LED strip. The constant $K$ is a scaling factor dependent on the units of observer score and $n$ determines the slope for the average luminance of the wooden cover. Both $c$ and $c_{1}$ are constants for scaling the upward LED strip luminance where $c_{1}$ is a normalisation constant. As observers adapt to the highest luminance in the scene, which is often the upward LED strip, lower luminance areas appear less bright as the observers' adaptation changes in response to a change in the LED strip luminance. The adaptation state is taken into account by including the LED strip luminance in the model.

The parameters in (1) are determined by fitting the experimental data for the average observer. The resulting fitting parameters were: $K=8.23, n=0.75, c=0.52$ and $c_{1}=256.5$. The score predicted by the model results in a very high coefficient of determination $\left(R^{2}=0.94\right)$ and a very small root mean square error (RMSE) of 0.57 . This indicates that the average observer scores can be accurately estimated based on the average luminance of the cover and LED strip.

Figure 8 shows the average observer score of each lighting scene plotted versus the average luminance of cover and upward LED strip for the middle step. Note that the data points of the dark scene in both wooden covers have very low luminance values $\left(\leq 0.001 \mathrm{~cd} / \mathrm{m}^{2}\right)$ and are not depicted in the figure because of the logarithmically scaled axes. Model (1) is used since it has a higher $R^{2}$ and was fitted using all data points (including the dark scenes). It is shown as a grey surface.

The results confirm previous findings; as the average luminance of the cover (upward LED strip) increases the observers score increases (decreases). As the luminance of the upward LED strip increases, the luminance on the cover needs to increase to achieve a similar or higher score, as more light is needed to compensate the high upward luminous intensity.

When comparing average observer scores of both covers at approximately equal luminance conditions, the dark-brown cover had, on average, higher scores. This is interesting as previous results show that the arithmetic mean of the average observer scores were higher for the light-brown cover. A possible explanation could be that a higher perceptual contrast is obtained with the dark-brown cover between the cover and LED strip. However, more energy is required to achieve an equal average luminance value for the dark-brown cover compared to the light-brown cover, as the latter has a higher reflection coefficient. 


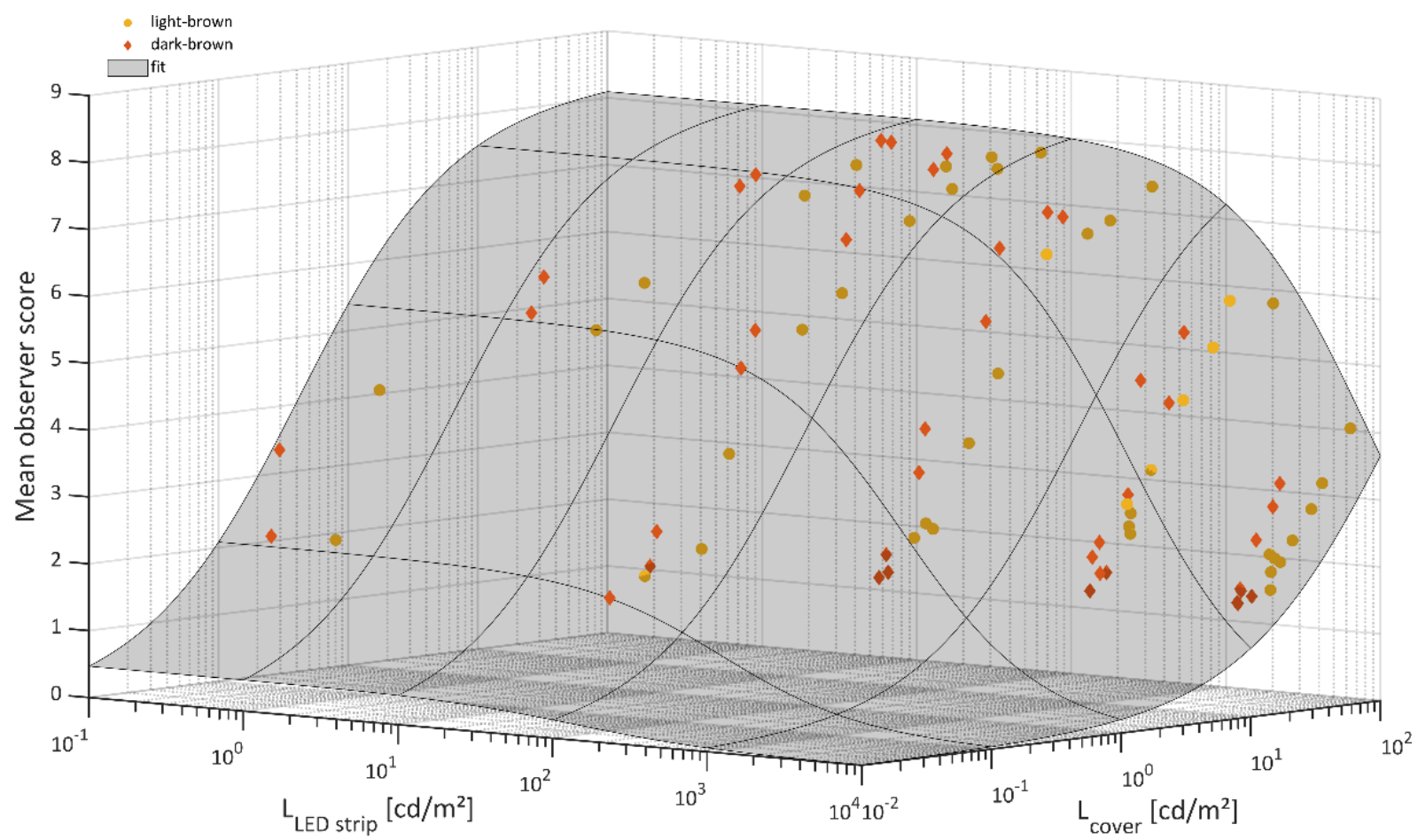

Figure 8-Average observer score plotted versus average luminance of the middle step for the cover and upward LED strip. The light- and dark-brown covers are denoted with light-brown circles and dark-brown diamonds, respectively. The fitted model is shown as a grey transparent surface.

Figure 9 shows a contour plot with the predicted observer scores using the fitted parameters for model (1). The average observer scores are denoted as a circle in their respective colour. It is important to note that some luminance ranges have no data points and therefore could be unreliable. Observers were informed that a score of five was the limit of barely adequate lighting to descend the stairs in a safe manner. Therefore, colours ranging from light to dark green are used to indicate adequate lighting settings for the investigated lighting scenes. Based on the predicted observer score, when the luminance of the cover and upward LED strip is approximately equal (see dashed diagonal line), the limit of barely adequate for the wooden cover was, on average, approximately $0.75 \mathrm{~cd} / \mathrm{m}^{2}$, whereas approximately $4.5 \mathrm{~cd} / \mathrm{m}^{2}$ or more resulted in a score of seven or higher. When no upward LED strip intensity is used, a predicted score of eight or higher is obtainable with an approximately $50 \mathrm{~cd} / \mathrm{m}^{2}$ wooden cover. The CIBSE lighting guide 9 specified that a luminance of no greater than $300 \mathrm{~cd} / \mathrm{m}^{2}$ should be selected for light fittings in order to avoid glare. A vertical dashed line in Figure 9 shows this threshold. Other lighting specifications reported the illuminance, with recommended values ranging from $75 \mathrm{~lx}$ to $150 \mathrm{~lx}$. Assuming the wooden covers were lambertian surfaces, calculated recommended luminance ranges would be approximately between $16.2-32.5 \mathrm{~cd} / \mathrm{m}^{2}$ for the light-brown cover $\left(\rho_{D 65}=68 \%\right)$ and between $5.7-11.5 \mathrm{~cd} / \mathrm{m}^{2}$ for the dark-brown cover $\left(\rho_{D 65}=24 \%\right)$. These luminance values corresponded with a predicted score between 7 and 8 , indicating the validity of the predicted scores for these luminance ranges. 


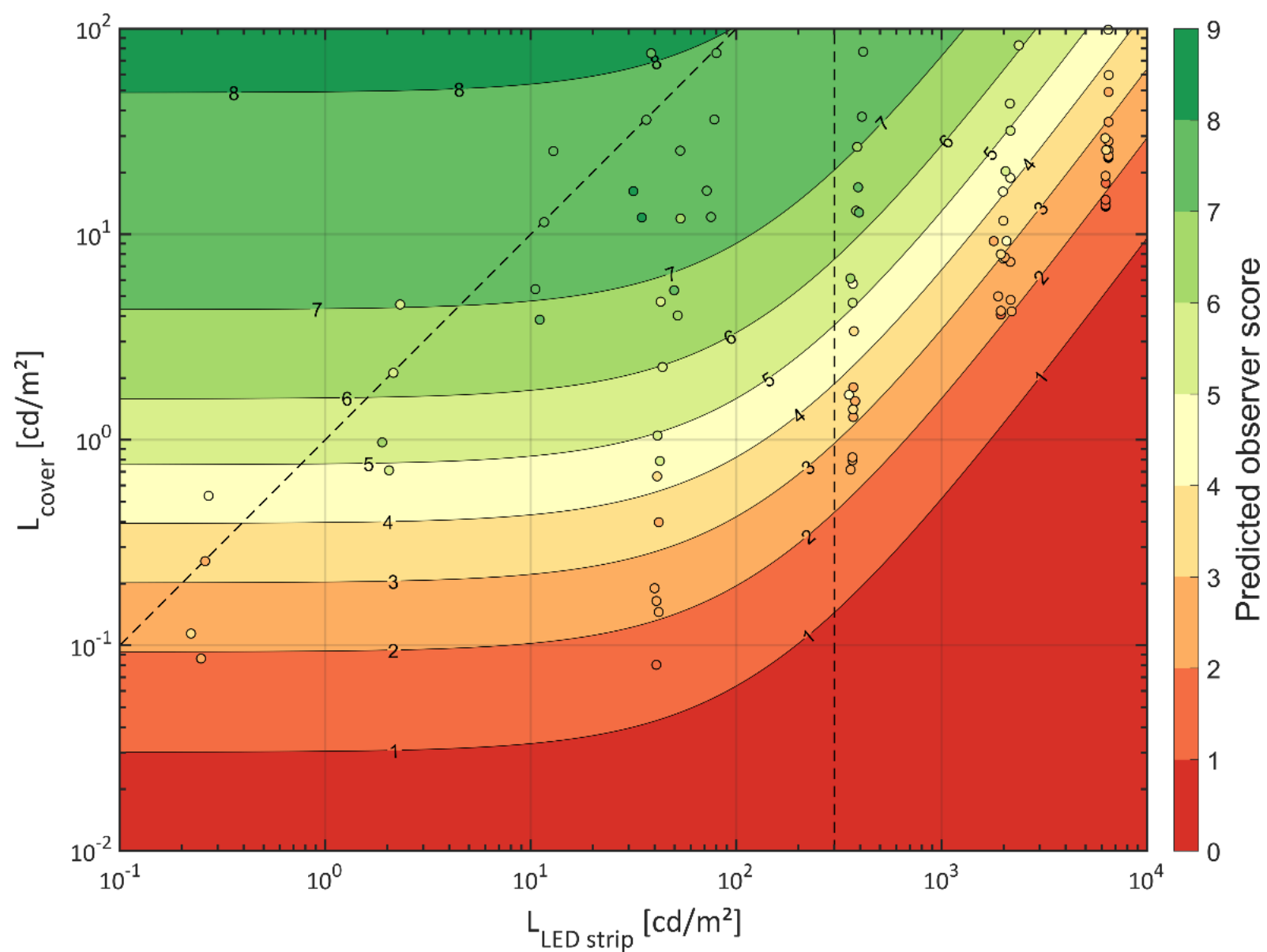

Figure 9 - Iso-contour plot of the predicted scores using the fitted model. Black solid lines depict the iso-lines for predicted scores. The scores are colour coded from red to green representing scores from zero to nine, respectively. The average observer scores for each scene is denoted as a coloured circle. The vertical dashed line denotes a luminance of $300 \mathrm{~cd} / \mathrm{m}^{2}$ for the upward LED strip.

\section{CONCLUSION}

Lighting is an important aspect regarding stair safety design. There are several standards and guidelines that established several lighting specifications. However, many factors can influence stair safety and it remains difficult to specify quantitative values for good stair lighting. An experiment has been conducted with a top-to-bottom view as this has the highest risk for serious fall injuries. Elderly were asked to assess different lighting scenes in terms of the perceived safety of descending a staircase. Based on previously conducted exploratory studies, choices were made regarding (combinations of) lighting groups on the staircase and cover colour of the steps for the conducted experiment. A mockup staircase was used to investigate three luminaire groups, a LED strip built into the handrail illuminating the whole staircase and two LED strips built into the stair nose illuminating upward and downwards. Two wooden stair covers, with light- and dark-brown textures, were investigated.

In the first part of the experiment, observers adjusted the luminous intensity indicating the preferred intensity for several lighting groups. Results showed that as observers set a higher intensity of the upward LED strip, the observers' adjusted intensity of either the downward or handrail LED strip increased, resulting in an increasing average luminance of the cover. When using the upward LED strip in combination with the handrail LED strip or downward LED strip, the latter was preferred. Likely because of the higher achievable average luminance on the steps with the downward LED strip in comparison to the handrail LED strip. 
For the second part of the experiment, observers scored several lighting scenes on stair safety with scores ranging from zero to ten, with decreasing scores indicating lower perceived safety. The interobserver reliability indicated that observers responded consistently among each other and that the average observer is a good representation of the data. The results show that as the luminous intensity of the upward LED strip increases the score decreases. The score increases as the intensity of the downward or handrail LED strip increases, resulting in an increasing average luminance on the step cover. Furthermore, higher upward LED strip intensities need high average luminance on the steps. Using only the upward LED strip as a light source resulted in very low overall scores for any luminous intensity and for both covers, with, on average, scores below three. Despite these bad scores, the presence of the upward LED strip was important, as it functioned as a contrast strip, even when no light was emitted. Previous literature showed that placing a contrast strip at the edge of the stair nose increases the visibility of the steps. Therefore, in practical situations where no upward LED strip is built into the stair nose, a contrast strip is recommended. Using the upward LED strip in combination with the downward or handrail LED strip can still result in a good score, although the upward luminous intensity should be limited. Using such lighting scenes in a practical application could be difficult, because the intensity of the upward LED strip is not only dependent on the luminance of the cover, but also on the surrounding luminous environment, which can change rapidly when used in a daylight environment. Therefore, it is advisable to use such lighting settings with caution.

A model with four parameters has been created that accurately $\left(R^{2}=0.94\right)$ predicts the observer scores using the average luminance of the upward LED strip and cover. A contour plot was presented with several luminance threshold levels for the upward LED strip and cover based on the predicted observer score of the model. An average luminance value of approximately $4.5 \mathrm{~cd} / \mathrm{m}^{2}$ on both the upward LED strip and wooden cover results in a predicted observer score of seven.

Note that the results are only an indication towards the preferred luminance levels of elderly observers in a night-time situation given the tested scenarios. These results are not directly transferable to other staircases, as more work is required to validate these luminance levels for other scenarios. Nonetheless, the presented work is a preliminary step towards lighting specifications using preferred luminance level thresholds for elderly people in a night-time situation for stairs. However, only three luminaire groups were tested and with flexible light sources, such as LED and OLED, more elaborate lighting designs are integrable within the stair design, offering more possibilities for the lighting designers. However, the increased flexibility could also lead to inadequate staircase lighting. Therefore, future studies could focus on testing a variety of luminaire groups and spatial configuration. The covers had an influence on the average luminance. However, results showed no significant effect on perceived safety between the covers for equal luminous intensities of the luminaires. Future work could also consist of testing several covers with varying reflection coefficients and colours/textures because these have a major impact on luminance levels. Another aspect could be to test several population groups, e.g. testing variations between preferred luminance threshold levels between young and elderly. Finally, the present study only focussed on perceived safety due to constructional limitations of the experimental setup, however future work could involve practical safety tests of different staircase lighting conditions.

\section{DISCLOSURE STATEMENT}

The authors report no declarations of interest.

\section{ACKNOWLEDGEMENTS}

The experiment was conducted in a facility of the non-profit organization 'Happy Aging' and conducted in collaboration with UHasselt, BBRI and KULeuven. This research was supported by Impulse Fund KU Leuven [IMP/16/027] and the Flanders Innovation \& Entrepreneurship government agency [project 
'Groen Licht Vlaanderen 2020' IWT.100955]. The authors want to express their gratitude towards the observers.

\section{REFERENCES}

[1] Injury Facts ${ }^{\circledR}, 2017$ Edition. Itasca, IL: National Safety Council, 2017.

[2] Milisen K, Leysens G, Vanaken D, et al. Vlaamse richtlijn 'Valpreventie bij thuiswonende ouderen'. Antwerpen, www.valpreventie.be (2017).

[3] Startzell JK, Owens DA, Mulfinger LM, et al. Stair negotiation in older people: A review. J Am Geriatr Soc 2000; 48: 567-580.

[4] Novak AC, Komisar V, Maki BE, et al. Age-related differences in dynamic balance control during stair descent and effect of varying step geometry. Appl Ergon 2016; 52: 275-284.

[5] Roys MS. Serious stair injuries can be prevented by improved stair design. Appl Ergon 2001; 32: 135-139.

[6] Winters S, Ceulemans W, Heylen K, et al. Wonen in Vlaanderen anno 2013. De bevindingen uit het Grote Woononderzoek 2013 gebundeld. Leuven: Steunpunt Wonen, https://steunpuntwonen.be/Documenten_2012-2015/Onderzoek_Werkpakketten/gwovolume-1-eind.pdf (2015, accessed 8 April 2019).

[7] Vanderstraeten L, Ryckewaert M. Grote Woononderzoek 2013. Deel 3. Technische woningkwaliteit. Leuven: Steunpunt Wonen, https://steunpuntwonen.be/Documenten_20122015/Onderzoek_Werkpakketten/gwo-volume-2-deel-3-eind.pdf (2015, accessed 8 April 2019).

[8] Carter SE, Campbell EM, Sanson-Fisher RW, et al. Environmental hazards in the homes of older people. Age Ageing 1997; 26: 195-202.

[9] Stevens M, Holman CDJ, Bennett N. Preventing Falls in Older People: Impact of an Intervention to Reduce Environmental Hazards in the Home. J Am Geriatr Soc 2001; 49: 1442-1447.

[10] Shaheen AF, Sourlas A, Horton K, et al. Effects of lighting illuminance levels on stair negotiation performance in individuals with visual impairment. J Electromyogr Kinesiol 2018; 39: 8-15.

[11] Danschutter S, Janssens K. Improving the accessibility and safety of stairs by providing adequate lighting and sufficient contrast. Gerontechnology 2016; 15: 78-78.

[12] Janssens K, Vanrie J, Quartier K, et al. Light: Towards an Inclusive Perspective. In: Di Bucchianico G, Kercher P (eds) Advances in Design for Inclusion. Cham: Springer International Publishing, 2016, pp. 155-165.

[13] Templer J. The staircase: studies of hazards, falls, and safer design, https://books.google.be/books?hl=en\&lr=\&id=n8V546i9zGAC\&oi=fnd\&pg=PP11\&dq=The+Stai rcase:+Studies+of+Hazards,+Falls+and+Safer+Design\&ots=0lwdNVyYrG\&sig=60ly2g8tF0tufXge TVuFS6J5DUk (1995, accessed 26 December 2018).

[14] NBN. Light and lighting - Lighting of work places - Part 1: Indoor work places. Bureau voor Normalisatie, 2011.

[15] Deneyer A, D 'herdt P, Deroisy B, et al. PRAKTISCHE EN TECHNISCHE GIDS VOOR DE VERLICHTING VAN WONINGEN, https://www.wtcb.be/homepage/index.cfm?cat=publications\&sub=search\&id=CSTC1103999 (2011). 
[16] Barker B, Brawley B, Burnett D, et al. Lighting and the Visual Environment for Seniors and the Low Vision Population (RP-28-16). Illuminating Engineering Society, 2016.

[17] LG09 Lighting Guide 09: Lighting for Communal Residential Buildings - LG9. CIBSE, 2013.

[18] Alderson A. Stairs, ramps and escalators: Inclusive design guidance. RIBA Publishing, 2010.

[19] Akashi M, Akizuki M, Cobham M, et al. CIE 227:2017 Lighting for Older People and People with Visual Impairment in Buildings. CIE 227:2017, Vienna, Austria. Epub ahead of print 3 October 2017. DOI: 10.25039/TR.227.2017.

[20] Zietz D, Hollands M. Gaze Behavior of Young and Older Adults During Stair Walking. J Mot Behav 2009; 41: 357-366.

[21] Shrout PE, Fleiss JL. Intraclass correlations: uses in assessing rater reliability. Psychol Bull 1979; 86: 420-8.

[22] Koo TK, Li MY. A Guideline of Selecting and Reporting Intraclass Correlation Coefficients for Reliability Research. J Chiropr Med 2016; 15: 155-163.

[23] O. McGraw K, P. Wong S. Forming inferences about some intraclass correlation coefficients. Psychol Methods 1996; 1: 30-46.

[24] Lee KM, Lee J, Chung CY, et al. Pitfalls and Important Issues in Testing Reliability Using Intraclass Correlation Coefficients in Orthopaedic Research. Clin Orthop Surg 2012; 4: 149-155.

[25] R Core Team. R: A Language and Environment for Statistical Computing, https://www.rproject.org/ (2019).

[26] Bates D, Mächler M, Bolker B, et al. Fitting Linear Mixed-Effects Models Using \{lme4\}. J Stat Softw 2015; 67: 1-48. 